\title{
Cleaner Manufacturing of Critical Metals
}

\author{
FISEHA TESFAYE @i], ${ }^{1,3}$ NAIYANG MA, ${ }^{2,4}$ and MINGMING ZHANG ${ }^{2,5}$ \\ 1.—Johan Gadolin Process Chemistry Centre, Åbo Akademi University, Piispankatu 8, 20500 \\ Turku, Finland. 2.-ArcelorMittal Global R\&D, East Chicago, USA. 3.-e-mail: \\ fiseha.tesfaye@abo.fi. 4.—e-mail: Naiyang.Ma@arcelormittal.com. 5.—e-mail: Mingming.Zhang@ \\ arcelormittal.com
}

Today, a reliable supply of certain metals, including the minor metals that are used in small quantities for a variety of economically significant applications, e.g., smart phones, laptops, solar cells, electric vehicles, etc., and national defense applications, are at risk. To address this challenge of metals supply risk, the European Commission in 2017 and the United States in 2018 have created lists of 27 and 35 critical raw materials (CRMs), respectively. ${ }^{1,2}$ Among the CRMs lists, metals such as $\mathrm{Mn}, \mathrm{V}$, and $\mathrm{Cr}$ are also critical to China. For example, the demand for vanadium in China is projected to double from 2010 to 2025 because of its continued use in steelmaking (including new steelhardening requirements) and its potential for application in a new battery technology used for largescale renewable energy storage. ${ }^{2}$ In general, the CRMs lists, which are subject to review and update from time to time, reflect raw materials of high economic importance and of high supply risk. Figure 1 shows the high economic importance versus supply risk of selected metals.

In order to be able to insure the continuity of the CRMs supply, attention has turned from primary sources, which are being depleted and linked to geopolitical issues, to alternative sources such as industrial side-streams, municipal waste-streams like end-of-life electronic devices, and other secondary sources like agricultural byproducts. Emphasis should also be placed on advancing the prevailing primary and secondary resources processing technologies to reduce environmental footprints and to maximize CMRs production with highenergy efficiency.

In a $2019 \mathrm{JOM}$ topic on Recycling of Industrial Metals and Materials: Trends in Recent Research, ${ }^{3}$ the articles were focused on various improvements in process flowsheets that send intermediate

Fiseha Tesfaye, Naiyang Ma, and Mingming Zhang are the JOM Guest Editors for the Recycling and Environmental Technologies Committee of The Minerals, Metals \& Materials Society. products and residues back as feedstock to a process. In the present issue, ten articles are presented which mainly cover hydrometallurgical and pyrometallurgical aspects of processing secondary resources. The papers are mostly devoted to contribute to developing feasible options for optimal and environmentally friendly ways of producing the critical metals from secondary sources. Critical metals recycling from end-of-life electronic devices were at the core of discussions. The organizers of this special issue believe that the papers make an impact on current research to enable the circular economy of critical metals and efforts to curb environmental issues.

The first two papers propose optimized hydrometallurgical processing steps that will increase the recovery of precious metals. "Ultrasound-Assisted Silver Leaching Process for Cleaner Production" by Haoyu $\mathrm{Li}$ et al. proposes a separation method for recycling of silver from lead-zinc tailings by an ultrasound-assisted leaching process. After experimental investigations, including the effects of the ultrasonic irradiation on the leaching process, the authors claim to have introduced an integrated process that is highly efficient and environmentally friendly for silver recovery. The second paper, "Effect of Oxidative Pretreatment and Lead Nitrate Addition on the Cyanidation of Refractory Gold Ore" by Faraz Soltani et al., discusses the effect of oxidative pretreatment and lead nitrate addition on the recovery of gold through cyanidation of Zarshuran refractory gold ore. Their study suggests that, in the presence of $500 \mathrm{~g} / \mathrm{t}$ of lead nitrate, the recovery of gold may be improved by about $10 \%$. Concerning the environmental issues associated with high cyanide consumption in gold leaching, the authors propose a further study on the cyanide consumption of copper ions in the leaching process.

The third paper, "Separation and Extraction of Valuable Metals from Electroplating Sludge by Carbothermal Reduction and Low Carbon Reduction Refining" by Lei Tian et al., discusses the 


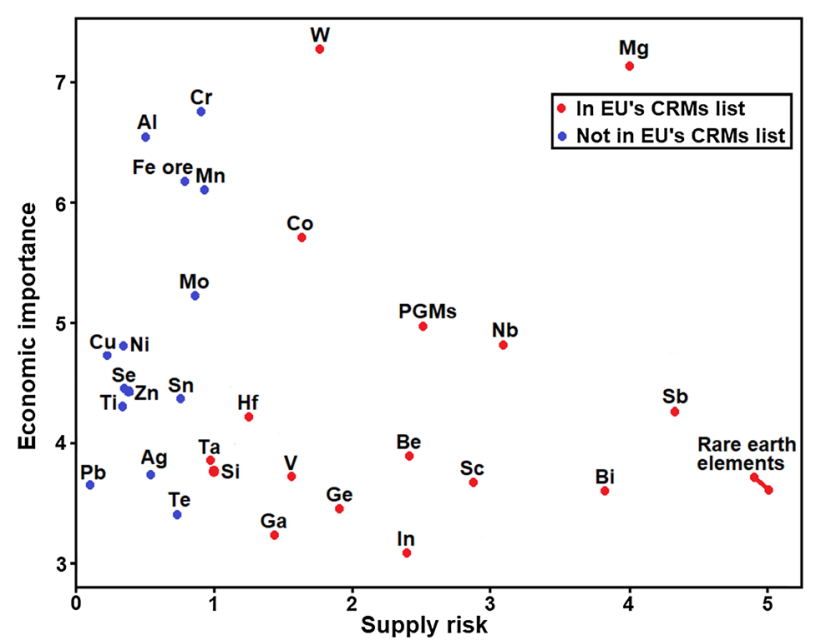

Fig. 1. Criticality of selected metals which were assessed by the European Commission in 2017. Data adapted from Ref. 1.

recovery of metals, including critical metals like nickel and tin, through carbothermal reduction and refining.

The article "Recovery of Scandium from Bauxite Residues by Selective Sulfation Roasting with Concentrated Sulfuric Acid and Leaching" by Fanyue Meng et al. investigates the reclaiming of scandium from bauxite residue by selective sulfation roasting and water leaching. Their work is one example where metallurgical roasting is applied as a pretreatment before the subsequent hydrometallurgical treatment for optimal recovery of valuable metals.

The next article, "Recycling of Discarded Tubular Lights for Recovery of Rare Earth Values" by Himanshu Tanvar et al., evaluates the potential of discarded tubular lights as a secondary source of rare earth elements (REEs). The authors focus on a two-step recovery of $\mathrm{Y}, \mathrm{Eu}, \mathrm{Ce}$, and $\mathrm{Tb}$ through leaching and microwave treatment followed by another leaching. The article "Comparison of Different Leaching Media and their Effect on REEs Recovery from Spent Nd-Fe-B Magnets" by Fupeng Liu et al. presents experimental investigations for the recovery of REEs from $\mathrm{Nd}-\mathrm{Fe}-\mathrm{B}$ magnet waste. The authors studied the effects of different amounts of leachants and high-purity REEs recovery through precipitation methods.

The article "Layer Growth in Co(W)-Zn Systems at Hard Metal Recycling" by Nadine Koerbler et al. describes recycling of Co and $\mathrm{W}$ from materials in the $\mathrm{Co}(\mathrm{W}) \mathrm{Zn}$-system. They studied the effects of temperature, duration and $\mathrm{W}$ content on the recycling. Recovery of nickel, which is an important component of the state-of-the-art lithium ion battery production, is reported in "High Purity Nickel Recovery from an Industrial Sidestream Using Concentration and Liquid-Liquid Extraction Techniques" by Fang $\mathrm{Hu}$ et al. The methodology comprises an initial evaporation step to achieve $\mathrm{Ca}$ removal, followed by impurity ( $\mathrm{Ca}, \mathrm{Mg}$ ) and valuable $(\mathrm{Co}, \mathrm{Ni})$ elements separation via a two-step solvent extraction with organophosphorus extractants. The paper, "Liquid-Liquid Extraction and Reductive Stripping of Chromium to Valorize Industrial Effluent" by Srivastava et al. discusses a liquid-liquid extraction of chromium from an industrial effluent.

The last two articles focus on the production of manganese and molybdenum. The article "Recovery of High-Purity $\mathrm{MnO}_{2}$ from the Acid Leaching Solution of Spent Li-ion Batteries" by Chao Peng et al. introduces the possibility of hydrometallurgical recovery of $\mathrm{Mn}$ from the complicated pregnant leach solutions of Li-ion battery waste in oxide form. The authors also outline a feasible industrial process based on known unit processing steps. The last article, "Mechanism of Selective Precipitation of Molybdenum from Tungstate Solution" by Luqi Zeng et al., describes the effects of the reaction time, temperature, and CuS dose on the precipitation of Mo, elucidates the mechanism of Mo precipitation, and provides robust guidelines for the separation of Mo from tungstate solution.

To view or download any of these papers, follow the URL http://ink.springer.com/journal/11837/72/ $2 /$ page/ 1 to the table of contents page for the February 2020 issue (vol. 72, no. 2).

\section{ACKNOWLEDGEMENTS}

The authors are grateful to the Academy of Finland (Decision number 311537) for financial support.

\section{REFERENCES}

1. European Commission, Communication from the Commission to the European Parliament, the Council, the European Economic and Social Committee and the Committee of the Regions on the 2017 list of Critical Raw Materials for the EU. http://eur-lex.europa.eu/legal-content/EN/ALL/?uri=COM:20 17:0490:FIN. Accessed 18 Oct 2019.

2. M. Humphries, Critical Minerals and U.S. Public Policy. Congressional Research Service (CRS), Report, R45810 (2019). http://EveryCRSReport.com. Accessed 20 Nov 2019.

3. D.E. Verhulst, F. Tesfaye, and M.E. Schlesinger, JOM 71, 3164 (2019). https://doi.org/10.1007/s11837-019-03663-w.

Publisher's Note Springer Nature remains neutral with regard to jurisdictional claims in published maps and institutional affiliations. 